\title{
The Relationship between Cutaneous Wounds Made on Obese Mice or Those with Decreased Body Weight and Serum Leptin Level
}

\author{
Tamae Urai', Haryanto', Kanae Mukai², Tatsuhiko Matsushita ${ }^{3}$, Kimi Asano1, $^{1}$ \\ Yukari Nakajima1, Mayumi Okuwa², Junko Sugama ${ }^{2,4}$, Toshio Nakatani2* \\ ${ }^{1}$ Department of Clinical Nursing, Graduate Course of Nursing Science, Division of Health Sciences, Graduate \\ School of Medical Sciences, Kanazawa University, Kanazawa, Japan \\ ${ }^{2}$ Faculty of Health Sciences, Institute of Medical, Pharmaceutical and Health Sciences, Kanazawa University, \\ Kanazawa, Japan \\ ${ }^{3}$ Division of Clinical Radiology Service, Kyoto University Hospital, Kyoto, Japan \\ ${ }^{4}$ Wellness Promotion Science Center, Institute of Medical, Pharmaceutical and Health Sciences, Kanazawa \\ University, Kanazawa, Japan \\ Email: "nakatosi@staff.kanazawa-u.ac.jp
}

Received 27 April 2016; accepted 5 August 2016; published 8 August 2016

Copyright (C) 2016 by authors and Scientific Research Publishing Inc.

This work is licensed under the Creative Commons Attribution International License (CC BY).

http://creativecommons.org/licenses/by/4.0/

(c) (7) Open Access

\section{Abstract}

Purpose: Not all obese people have hyperglycemia. We wondered about the healing progress in obese people without hyperglycemia. The purpose of this study is to observe the cutaneous wound healing process. Methods: Three-week-old male mice were fed high-fat diets (containing $60 \%$ fat) in the diet group, and commercial diets in the control group, ad libitum for 15 weeks. Circle-fullthickness cutaneous wounds were made on the dorsal skin of mice. From day 0 to day 15 after wounding, we analyzed wound healing process. We measured the blood concentration of leptin, and observed the distribution of leptin-positive cells in each wound. Results: Mean body weight, the areas of subcutaneous fat and visceral fat, and the weight of epididymal fat in the diet group were significantly greater than those in the control group at 15 weeks after feeding. The diet group did not feed on the diet after wounding; their body weight decreased remarkably to the level of the control group. The ratio of wound area, re-epithelialization, and collagen fibers did not differ between the diet and control groups on each day. The blood concentration of leptin in the diet group was significantly greater than that in the control group before wounding and until day 6 after wounding (day 0, 10 hour and day 1 : $p<0.01$, day 6: $p<0.05$ ). Conclusion: The results show

\footnotetext{
"Corresponding author.
}

How to cite this paper: Urai, T., Haryanto, Mukai, K., Matsushita, T., Asano, K., Nakajima, Y., Okuwa, M., Sugama, J. and Nakatani, T. (2016) The Relationship between Cutaneous Wounds Made on Obese Mice or Those with Decreased Body Weight and Serum Leptin Level. Health, 8, 1015-1028. http://dx.doi.org/10.4236/health.2016.811105 
that the wound healing process is similar between obese and non-obese mice, and that the decrease in the leptin level in the obese mouse to that in the non-obese mouse may depend on the decrease of body weight of obese mouse.

\title{
Keywords
}

\author{
Obesity, High-Fat Diet, Wound Healing, Leptin, Tension
}

\section{Introduction}

Obesity is excessive fat accumulation [1] [2]. The World Health Organization (WHO) has defined obesity as a body mass index (BMI) equal to or above 30 [3]. On the other hand, the Japan Society for the Study of Obesity (JASSO) decided to define BMI $\geq 25$ as obesity [2] and Kanazawa M et al. proposed that BMI $\geq 25$ is the appropriate criteria for obesity in Japan and the Asia-Oceania region [1]. Obesity is a major cause of type 2 diabetes [4] which is clinically shown hyperglycemia [5] [6]. However, Japanese Multi-Institutional Collaborative Study [7] indicated that not all obese people have hyperglycemia. The proportion of hyperglycemic men with BMI 26 - 27.9, 28 - 29.9, or $\geq 30$ was $11.3 \%, 15.0 \%$, or $15.4 \%$, respectively. Similarly, the proportion of hyperglycemic women was $11.8 \%, 16.4 \%$, or $19.4 \%$, respectively, for each classification of BMI. According to a previous population-based cross-sectional study [8] using data from the 2000-2011 national Medical Expenditures Panel Surveys, the proportion of non-diabetic respondents with BMI $\geq 30$ was $25.2 \%$ of 109,569 .

Although it is said that obesity is one of the causes of wound healing delay [9]-[11], it is possible that the wound healing of obese men with type 2 diabetes, hyperglycemia, is different from that of obese men without type 2 diabetes. Some previous studies reported wound healing delays in individuals with diabetes [9] and a hyperglycemic state [10] [11]. The impaired healing that occurs in individuals with diabetes involves hypoxia, dysfunction in fibroblasts and epidermal cells, impaired angiogenesis and neovascularization, high levels of metalloproteases, damage from reactive oxygen species and advanced glycation end-products, decreased host immune resistance, and neuropathy [9]. Wound closure was slower in ob/ob mice, and ob/ob animals that had decreased wound collagen accumulation [10]. Hyperglycemic rats showed delayed healing with the presence of deep ulceration and incomplete epithelialization up to day 14, and there was an immature collagen fiber network with poor cross-linkage in diabetic rats [11]. Therefore, hyperglycemia affects collagen accumulation in wounds.

An obese state was also introduced as one of the factors affecting wound healing. Factors related to wound impairment in obesity were classified to three categories: local wound conditions, factors altering immune and inflammatory responses, and associated diseases and conditions [9]. Concretely, local wound conditions included factors such as decreased vascularity in adipose tissue, skin folds harboring micro-organisms, friction caused by skin on skin, increased wound tension, and increased tissue pressure. Factors altering immune and inflammatory responses included adipokines, cytokines and chemokines. Associated diseases and conditions included factors such as hard to reposition, atherosclerosis, and type 2 diabetes [9]. In obese mice there was delayed wound contraction and re-epithelialization [12] [13]. Obesity has various factors that impair wound healing; one of these factors is hyperglycemia. Thus, we concluded that an experimental animal obese model without hyperglycemia was needed to evaluate intrinsic factors of excessive fat accumulation on wound healing.

The concentrations of fasting blood sugar in animal models with type 2 diabetes are 295 (SD 66.8) in ob/ob mice and 229 (SD 21.4) mg/dl in GK rats (industry data, Japan SLC, Inc., Hamamatsu, Japan). On the other hand, that in normal C57BL/6NCrSlc male mice (standard chow feeding, 10-weeks-age) is 119 (SD 18.0) mg/dl (industry data, Japan SLC, Inc., Hamamatsu, Japan). According to these data, the concentrations of fasting BS in models for type 2 diabetes are approximately $200-400 \mathrm{mg} / \mathrm{dl}$. The levels of blood sugar of animal models fed with a high-fat diet in previous studies were consistent with these blood sugar levels: lower than about 200 $\mathrm{mg} / \mathrm{dl}$. The blood sugar levels of obese rats by Nascimento [12] [13] were about $122.4 \mathrm{mg} / \mathrm{dl}$ and $90 \mathrm{mg} / \mathrm{dl}$, and those by Pence [14] were about $200 \mathrm{mg} / \mathrm{dl}$. Therefore, the concentration of fasting blood sugar in the obese mouse model is proposed as lower than $200 \mathrm{mg} / \mathrm{dl}$ of blood sugar in the model for type 2 diabetes.

Although an obesity index for animals, like BMI is not present, Cattaneo [15], Nascimento [12] [13], and Pence [14] indicated that the weights of obese rodents fed with a high-fat diet were 57\%, 25.7\%, 29\%, and 28\% 
heavier than those of non-obese rodents fed with a normal diet, respectively. Thus, the weight of the obese mouse model is proposed as about $30 \%$ heavier than that of non-obese mice.

The purpose of the present study is to compare the cutaneous wound healing process of diet-induced obese mice without hyperglycemia with that of mice fed a commercial diet.

\section{Materials and Methods}

\subsection{Animals and Diets}

One hundred and thirteen C57BL/6CrSlc male mice aged 3 weeks and weighing 7.6 - 14.0 g were used (Sankyo Labo Service Corporation, Inc., Tokyo, Japan). They were caged individually in an air-conditioned room with a temperature of 25.0 (SD 2.0) degrees, and with light from 08.45 to 20.45 hours. Water and laboratory chow were given ad libitum.

Mice were randomly divided into diet and control groups. The control group $(n=55)$ was fed a commercial diet (CRF-1; Charles River Laboratories International, Inc., Kanagawa, Japan) and the diet group $(n=58)$ was fed a high-fat diet (58Y1 Lard 60\% kcal Diet; PMI Nutrition International, St. Louis, USA) for 15 weeks (the diet period). Table 1 shows the composition of the diets. The high-fat diet had 1.4 times the energy of the commercial diet of the control, and 6.1 times the fat.

For the evaluation of mice models, body weight and diet intake were measured weekly from the beginning of the experiment. After mice were fasted over $10 \mathrm{~h}$, glucose was assessed with GLUCOCARD (GT-1641; ARKRAY, Inc., Kyoto, Japan) at week 15 after feeding.

\subsection{Body Fat}

The degree of body fat was analyzed by three methods at 15 weeks after feeding. First, the thickness of subcutaneous fat was measured using stained cutaneous. Second, the areas of subcutaneous fat and visceral fat were analyzed using MRI. Third, the degree of epididymal fat was measured.

The thickness of subcutaneous fat was measured between dermis and muscle layers using sections stained with hematoxylin-eosin or azan. Images of the sections were obtained using a digital microscopic camera (DP2-BSW, Olympus Corporation, Tokyo, Japan) and then imported onto a computer. The measurements were performed using the software (DP2-BSW, Olympus Corporation, Tokyo, Japan). By observation with a light microscope using a $10 \times$ objective, three measurement sites of each section were selected, where nothing was crushed or torn. The mean thickness of the three sites was calculated.

The MR imaging studies were performed with 0.4 Tesla open-MR imaging system (APERTO Eterna; Hitachi Medical Corporation, Tokyo, Japan) with QD Wrist Coil. 3D T1-weighted fast spin echo images obtained from the transverse planes from the base of the tail to the upper edge of the diaphragm. The sequence parameter was field of view: $100.0 \times 81.3 \mathrm{~mm}$, matrix: $192 \times 156$, slice thickness: $1.0 \mathrm{~mm}$, number of images: 118, repetition time/echo time: 300/30 msec, number of signal averages: one, and receiver band width: $16.3 \mathrm{kHz}$. Then, the areas of subcutaneous fat and visceral fat were measured from cross-sectional images using image analysis software ImageJ ver. 1.42q (Wayne Rasband, National Institutes of Health, Bethesda, Maryland, USA). The fat delineation was carried out by manual boundary tracing. These variables were measured in 10 pieces, ranging from the base of the tail to the edge of the liver. Body fat was calculated for a total of 11 sheets per animal.

\begin{tabular}{ccc}
\multicolumn{3}{l}{ Table 1. Experimental high-fat diet composition. } \\
\hline component in $100 \mathrm{~g}$ & control & high-fat \\
\hline Protein & 22.4 & 23.6 \\
Carbohydrate & 54.5 & 26.8 \\
Fat & 5.7 & 34.9 \\
Energy (kcal) & 359 & 516 \\
\hline
\end{tabular}

The control group was fed commercial pellets (CRF-1; Charles River Laboratories International, Inc., Kanagawa, Japan). The diet group was fed a high-fat diet (58Y1 Lard60\%kcal Diet; PMI Nutrition International, St. Louis, USA). 
The epididymal fat was removed from the epididymis, was put on a weigh scale and the weight of epididymal fat was measured.

\subsection{Wounding Procedure}

Fifteen weeks after feeding with the high-fat diet or commercial diet, the mice were anesthetized with an i.p. injection of pentobarbital sodium ( $0.05 \mathrm{mg} / \mathrm{g}$ weight). After mice slept without pain reaction under anesthesia, two circular (6 mm in diameter) full-thickness skin wounds were made on the dorsal skin with a Kai sterile disposable biopsy punch (Kai Industries, Gifu, Japan). The day when wounds were made was designated as day 0 after wounding. Wounds were covered with hydrocolloid dressing (Tegasorb; 3M Health Care, Tokyo, Japan) to maintain a moist environment, and then the mouse was wrapped twice with sticky bandages (SKINERGATETM; Nichiban, Tokyo, Japan) that were changed every day.

\subsection{Macroscopic Observations}

The wound healing process was observed from day 0 to day 15 after wounding. Wound edges were traced on polypropylene sheets and photographs were taken every day. The traces on the sheets were captured with a scanner onto a personal computer, and the areas of wounds, as well as their ellipse major axis and ellipse minor axis were calculated using image analysis software Scion Image Alpha 4.0.3.2 (Scion Corporation, Frederick, Maryland, USA).

The shape of wound edges, degree of exudate, redness and edema of wound edges, color of granulation tissues, necrosis, and progress of new epithelium were observed. The ratios of the wound areas were calculated every day.

\subsection{Histological procedure}

Mice were euthanized with a lethal dose of pentobarbital sodium at day 0, 10 h, day 1, 3, 6, 9, 12, and 15 after wounding. The wounds and the surrounding normal skin were excised, stapled onto overhead projector sheets to prevent over-contraction of the samples, and fixed in $4 \%$ paraformaldehyde in $0.1 \mathrm{~mol} / \mathrm{L}$ phosphate-buffered saline ( $\mathrm{pH}$ 7.4) for $10 \mathrm{~h}$. The samples were divided into two parts: two-thirds and one-third. After these operations, the samples were dehydrated in an alcohol series, cleaned in xylene, and embedded in paraffin to prepare $5 \mu \mathrm{m}$ serial sections. These $5 \mu \mathrm{m}$ sections were stained with hematoxylin-eosin (HE), azan, and anti-leptin antibody.

After the removal of paraffin, the sections were treated with Target Retrieval Solution (pH9, 10×) for 20 minutes at solution temperature of 80 degrees for retrieval, and washed with $0.05 \mathrm{M}$ Tris-buffered saline (pH 7.6) for 5 min. Staining for leptin was performed immunohistochemically by using a polyclonal goat anti-leptin antibody (R\&D Systems, Minneapolis, MN), followed by a biotin-conjugated donkey anti-goat antibody and developed using the BCIP/NBT Alkaline Phosphatase system (ABC kit, Vector, Burlingame, CA) [16].

The degree of re-epithelialization was calculated as new epidermis length divided by wound length. Wound length was determined by measuring the distance between wound edges. For these measurements, image analysis software ImageJ ver. 1.42q (Wayne Rasband, National Institutes of Health, Bethesda, Maryland, USA) and HE staining sections were used.

For quantification of collagen fiber density, pictures of azan staining sections were taken on a range of granulation tissues at the wound center near the abdominal muscles. In granulation tissue, the collagen fibers which were blue-stained were selected and the number of pixels of the collagen fibers was measured using Adobe Photoshop Elements 6.0 (Adobe System Inc., Tokyo, Japan). The number of pixels of granulation tissue at the wound center near the abdominal muscles was measured. Collagen fiber density was calculated by the number of pixels of collagen fibers divided by the number of pixels of granulation tissue.

\subsection{Blood Procedure}

For the evaluation of the obese model, 3 mice from each group were harvested 15 weeks after feeding. Blood samples were obtained by cardiac puncture under anesthesia followed by euthanasia. The blood was used for measuring high-density lipoprotein cholesterol (HDL-C), total cholesterol, triglyceride (TG), aspartate aminotransferase (AST), alanine aminotransferase (ALT). Determination of HDL-C, total cholesterol, TG, AST, and ALT levels were outsourced to the manufacturer of these assays (LSI Medience Corporation, Tokyo, Japan). 
For the evaluation of leptin, mice were harvested at day 0, 10 h, day 1, 6, and 15 after wounding (Control group $n=4,5,6,6$, 5, Diet group $n=5,5,7,8,6$ ). Serum leptin levels were measured using MOUSE AND RAT LEPTIN ELISA (Biovendor Laboratory Medicine, the Czech Republi, COSMO BIO CO., LTD.).

\subsection{Statistical Analysis}

The data are presented as the mean (standard deviation). These were unpaired t-test comparisons between the diet group and the control group using a commercially available statistics package (JMP ${ }^{\circledR}$ 8.0.1; SAS Institute Inc., Cary, NC, USA). Differences were considered significant at $\mathrm{p}<0.05$.

This research was approved by the president of Kanazawa University and the experimental protocol and animal care were in accordance with the Guidelines for the Care and Use of Laboratory Animals of Kanazawa University, Japan (AP-101582).

\section{Results}

\subsection{Obese Mouse Model (Weight, Feeding, Fat, Glucose) (Table 2)}

The initial mean body weight of the diet group and control group did not differ. At 15 weeks after feeding, the body weight of the diet group was about $45 \%$ heavier than that of the control group. The control group consumed significantly more food than the diet group. However, the diet group consumed significantly more energy per week than the control group.

At 15 weeks after feeding, day 0 after wounding, the thickness of subcutaneous fat in the diet group was significantly thicker than that in the control group. The thickness of dermis in the diet group was significantly thinner than that in the control group (Figure 1(a) and Figure 1(b)). The weight of epididymal fat was significantly heavier than that in the control group. The area of body fat in the diet group was twice as large as that in the control group (Figure 1(c)).

Table 2. Body weight (BW), food consumption, thickness of dermis, subcutaneous fat, epididymal fat, area of body fat, fasting blood sugar (BS) in the control (C) and diet (D) groups.

\begin{tabular}{|c|c|c|c|c|}
\hline \multirow{2}{*}{ Parameter } & \multicolumn{2}{|c|}{$\mathrm{C}$} & \multicolumn{2}{|c|}{$\mathrm{D}$} \\
\hline & Mean & SD & Mean & SD \\
\hline Initial BW (g) & 11.4 & 1.3 & 10.9 & 1.7 \\
\hline Final BW (g) & 32.6 & 3.1 & $47.4^{*}$ & 4.2 \\
\hline Food consumption (g/week) & 23.3 & 3.4 & $18.2^{* *}$ & 2.9 \\
\hline Food consumption (kcal/week) & 83.7 & 12.2 & $93.8^{* *}$ & 15.1 \\
\hline Thickness of dermis $(\mu \mathrm{m})$ & 356.2 & 60.5 & $254.2^{*}$ & 58.5 \\
\hline Thickness of subcutaneous fat $(\mu \mathrm{m})$ & 594.2 & 220.4 & $1366.5^{*}$ & 581.7 \\
\hline Epididymal fat (g) & 1.3 & 0.2 & $2.0^{*}$ & 0.6 \\
\hline Area of body fat $\left(\mathrm{mm}^{2}\right)$ & 1943.1 & 216.4 & 4062.1 & 172.5 \\
\hline Fasting BS (mg/dL) & 119.0 & 28.0 & $152.9^{*}$ & 51.5 \\
\hline HDL-C (mg/dL) & 67.7 & 3.2 & $124.3^{* *}$ & 10.2 \\
\hline Total cholesterol (mg/dL) & 92.7 & 5.9 & $177.0^{* *}$ & 23.3 \\
\hline TG (mg/dL) & 43.7 & 4.9 & 40.7 & 15.0 \\
\hline AST (IU/L) & 69.7 & 13.5 & 305.7 & 200.5 \\
\hline ALT (IU/L) & 24.0 & 4.6 & 348.0 & 265.7 \\
\hline
\end{tabular}

Body weight $(C=55, D=58)$; food consumption $(C=44, D=46)$; thickness of dermis, subcutaneous fat $(C=6, D=6)$; epididymal fat $(C=7, D=$ 8); area of body fat $(C=2, D=2)$; fasting blood sugar $(C=34, D=34)$; HDL-C, total cholesterol, TG, AST, ALT (C = 3, D = 3). ${ }^{*}{ }^{* *}$ Mean value was significantly different from that of the control group (unpaired t-test comparisons: ${ }^{*} \mathrm{p}<0.05,{ }^{* *} \mathrm{p}<0.01$ ). All parameters were measured on the day wounds were made (week 15, day 0). 


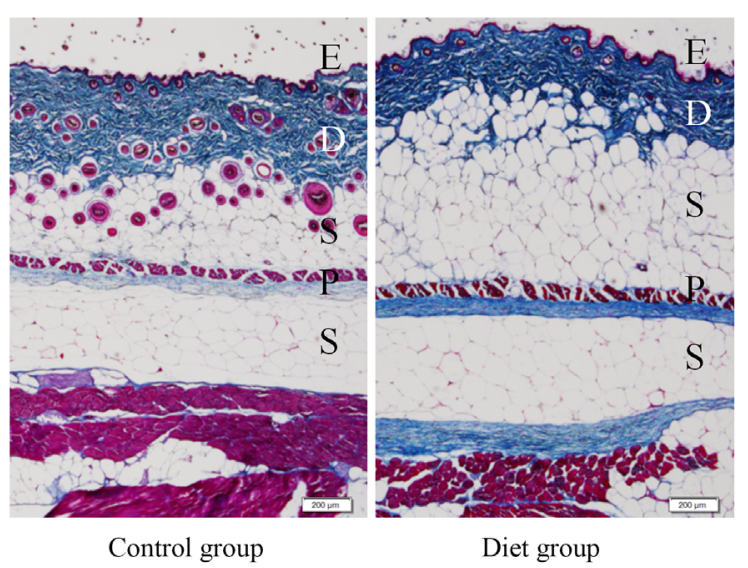

(a)

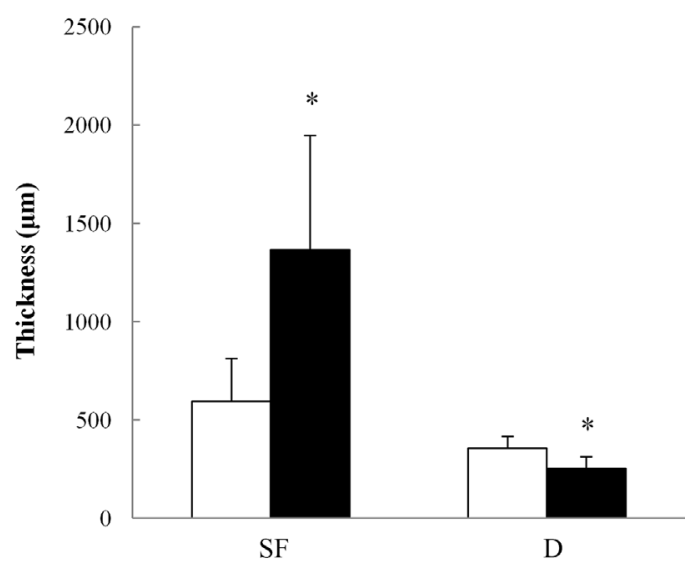

(b)

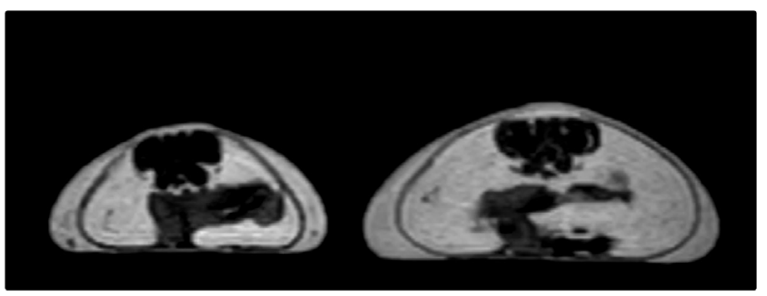

Control group

Diet group

(c)

Figure 1. Evaluation of body fat mass. (a) The dorsal skin of mouse (non-wounded). Sections were stained with azan. Magnification: $4 \times$. Scale bar $=200 \mu \mathrm{m}$. E: epidermis; D: dermis; S: subcutaneous adipose tissue; P: panniculus carnosus. (b) The thickness of dermis and subcutaneous fat. These sections were non-wounded skin, after 15 weeks of diet. Values are means, with their standard deviation represented by vertical bars. Control group $(\square) \mathrm{n}=6$, Diet group $(\boldsymbol{\bullet})$ $\mathrm{n}=6$. *Mean value was significantly different from that of the control group (unpaired t-test comparisons: $\mathrm{p}<0.05$ ). (c) The areas of subcutaneous fat and visceral fat. These subjects were non-wounded mice, after 15 weeks of diet. The MR imaging studies were performed with 0.4 Tesla open-MR imaging system with QD Wrist Coil. 3D T1-weighted fast spin echo images obtained transverse planes from the base of the tail to the upper edge of the diaphragm.

The fasting BS, HDL-C, and total cholesterol levels of the diet group were significantly higher than those of the control group. The BS level in the diet group, mean $152.9 \mathrm{~g} / \mathrm{dl}$, was lower than $200 \mathrm{mg} / \mathrm{dl}$ which is the minimum BS in diabetic model mouse.

\subsection{Wounds}

Wound healing progress in both groups seemed to be similar for 15 days. The shape of the wound in the diet group was oval. That in the control group seemed to be circular (Figure 2(a)). The area of the diet group on day 4 was the maximum size reached during wound healing, and the maximum size of the control group was on day 2. The day when the area became maximal was different between the two groups. Ratios of the areas on day 15 were diet group: 0.12 (SD 0.08), and control group: 0.08 (SD 0.03) $(\mathrm{p}=0.11)$. The ratio of wound area, the degree of re-epithelialization, and the density of collagen fiber were not different between the two groups throughout the experiment (Figures 2(b)-(d)).

We measured the differences between the major axis and minor axis of the wound every day to analyze wound tension. On day 0, the difference in the diet group: 1.96 (SD 0.57) $\mathrm{mm}$ was longer than that in the control group: 1.45 (SD 0.78 ) $\mathrm{mm}$. From day 2 to day 8 , the difference in the diet group was significantly greater than that in the control group. However, after day 9 , the wound shapes of both groups seemed to be circular. The difference in the diet group was roughly constant after day $11(1.00-1.25 \mathrm{~mm})$. The difference in the control group was also roughly constant after day $7(0.78-0.95 \mathrm{~mm})$. On day 15 , the difference between the major axis and minor axis of the wound was not significant between the two groups (Figure 2(e)). 


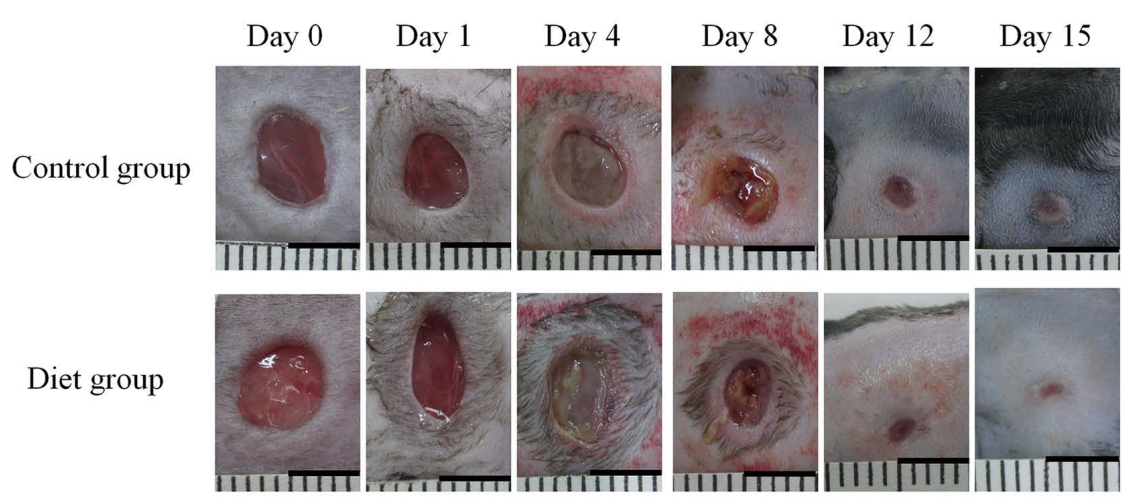

(a)

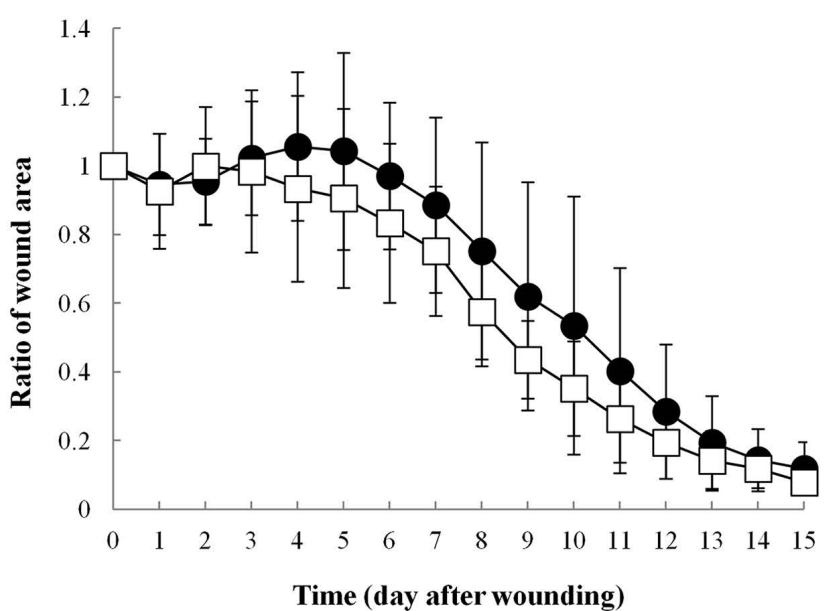

(b)

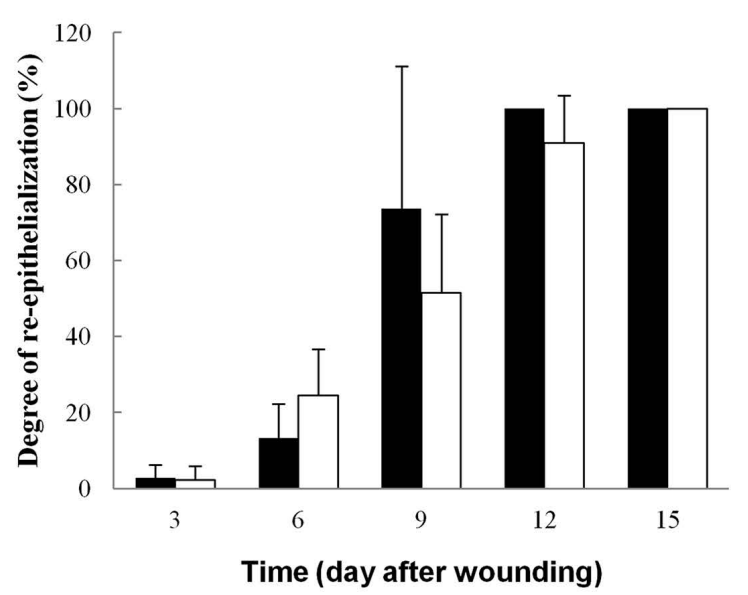

(c)

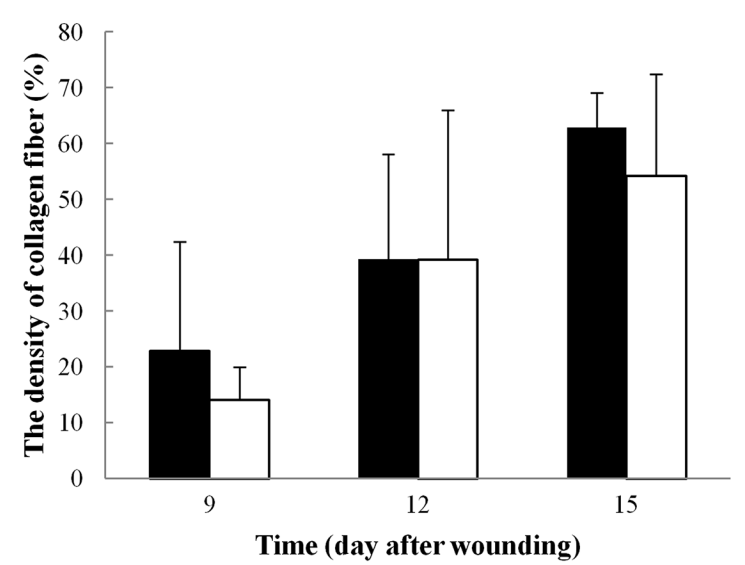

(d)

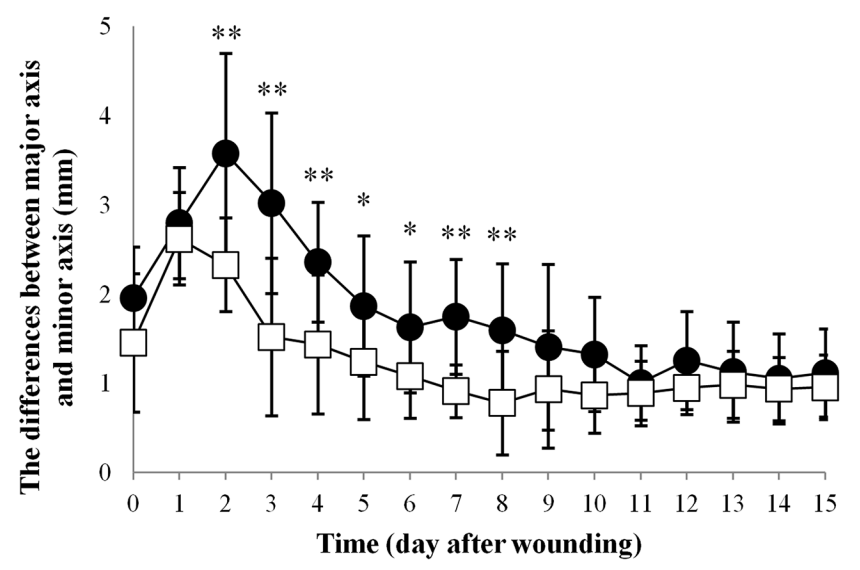

(e)

Figure 2. Evaluation of wound contraction, re-epithelialization and granulation. (a) Six mm in diameter wounds were made, and the healing process was recorded by photography. Bar $5 \mathrm{~mm}$. (b) The ratio of wound area was calculated as each day divided by day 0 . The area on day 0 was baseline. Control group $(\square) \mathrm{n}=12$, Diet group $(\bullet) \mathrm{n}=13$. (c) The degree of re-epithelialization was calculated as new epidermis length divided by wound length. Control group ( $\square$ ) $n=$ $6,7,6,6,6$, Diet group $(\bigcirc) n=4,6,6,5,5$. (d) The difference between major axis and minor axis of the wound. Control group $(\square) \mathrm{n}=11$, Diet group $(\bigcirc) \mathrm{n}=13$. (e) Quantification of collagen fiber density. Control group $(\square) \mathrm{n}=4$, Diet group $(0) n=4$. Values are means, with their standard deviation represented by vertical bars. *Mean value was significantly different from that of the control group (unpaired t-test comparisons: $\mathrm{p}<0.05$ ). 


\subsection{Body Weight Decreased after Wounding}

After wounding, body weight in the diet group decreased remarkably. On day 0 - 9, the weight of the diet group was significant higher than that of the control group. Consequently, mean body weights from day 10 to day 15 did not differ significantly between the two groups (Figure 3(a)). On day 15, the weight in the diet group was 26.4 (SD 0.9) g, and that in the control group was 24.6 (SD 0.4) g ( $\mathrm{p}=0.11$ ).

After wounding, the degree of diet intake decreased remarkably in both groups. In the control group, the degree of diet intake returned to the mean level of intake before wounding at 5 days after wounding. However, in the diet group, the diet intake was not restored to the mean level of intake until day 14 (Figure 3(b)).

\subsection{Leptin}

At 15 weeks after feeding, the day before wounding, the blood concentration of leptin in the diet group (42.3 (SD 3.5) ng/ml) was significantly higher than that in the control group (3.5 (SD 1.1) ng/ml) (Figure 4). At $10 \mathrm{~h}$ and day 1 after wounding, the concentrations in the diet group were (10 h: 44.9 (SD 0.7), day 1: 43.3 (SD 15.2) $\mathrm{ng} / \mathrm{ml}$ ) higher than those in the control group (10 h: 16.7 (SD 8.8), day 1: 11.3 (SD 7.1) ng/ml). At day 6 after wounding, the leptin concentration in the diet group was decreased remarkably to 14.7 (SD 14.5) ng/ml; however, it was significantly higher than that of the control group: 2.0 (SD 1.3) ng/ml. At day 15 after wounding, the leptin level in the diet group: 3.4 (SD 0.2) ng/ml, and the control group: 3.2 (SD 0.4) ng/ml, were almost the same and there was no significance between the two groups.

At 15 weeks after feeding, 0 days before wounding, leptin was detected in the epidermal layer, subcutaneous adipose tissue, sebaceous glands cell around hair follicles, and panniculus carnosus (Figures 5(a)-(c)).

After wounding, a lot of leptin-positive cells were detected throughout the wound and wound edges. At $10 \mathrm{~h}$ after wounding, the leptin-positive cells were present in the wound bed, they seemed to be inflammatory cells (Figure 6(a), Figure 6(b), Figure 6(e), and Figure 6(g)). The leptin-positive cells at the wound edge were present in subcutaneous adipose tissue, sebaceous gland cells around hair follicles, panniculus carnosus, and inflammatory cells in subcutaneous tissue (Figure 6(c), Figure 6(d), and Figure 6(h)).

At day 6 after wounding, the leptin-positive cells were present in granulation tissue and necrotic tissue, they seemed to be inflammatory cells or macrophages (Figure 7(a) and Figure 7(f)). In the diet group, the leptinpositive cells were present in the new-epidermis (Figure 7(b)). In the control group, the leptin-positive cells were present under the edge of the new-epidermis (Figure 7 (g)). The leptin-positive cells at the wound edge were present in subcutaneous adipose tissue (Figure 7(e) and Figure 7(i)).

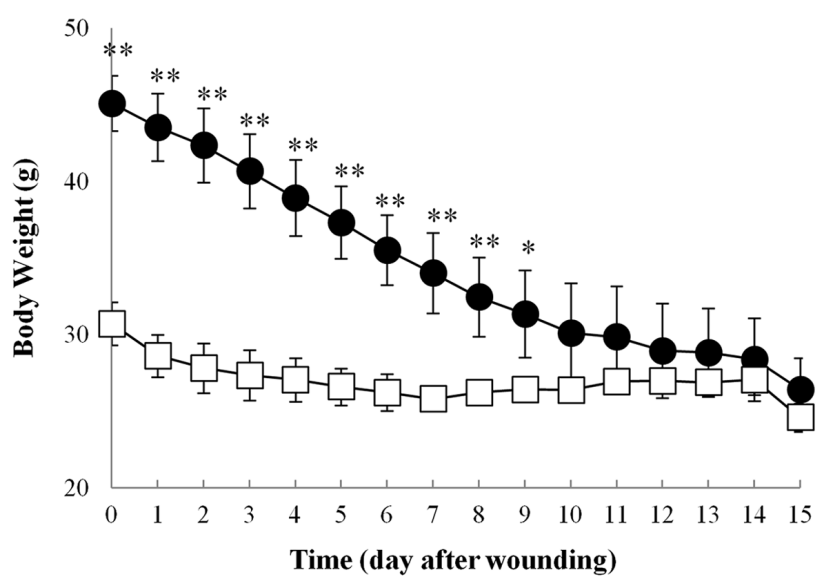

(a)

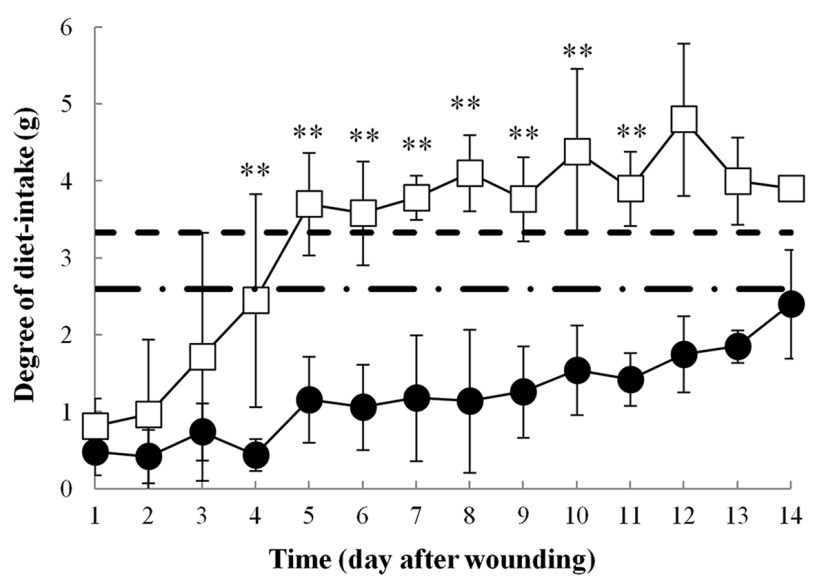

(b)

\footnotetext{
Figure 3. Body weight and feed intake after wounding. (a) Body weight after wounding. Control group ( $\square$ ) n $=5$, Diet group (O) $n=5$. (b) the degree of diet-intake after wounding. Control group ( $\square) \mathrm{n}=6$ (1 - 11 days), 2 (12 - 14 days), Diet group (O) $\mathrm{n}=5$ (1 - 11 days), 2 (12 - 14 days). Horizontal line (--) indicates means per day of control group diet-intake at 14 weeks before wounding (g/day). $n=44$. Horizontal line $\left(-\bullet_{-}\right)$indicates means per day of diet group diet-intake at 14 weeks before wounding (g/day). $\mathrm{n}=46$. Values are means, with their standard deviation represented by vertical bars. *, ** Mean value was significantly different from that of the control group (unpaired t-test comparisons: ${ }^{*} \mathrm{p}<0.05,{ }^{* *} \mathrm{p}<0.01$ ).
} 


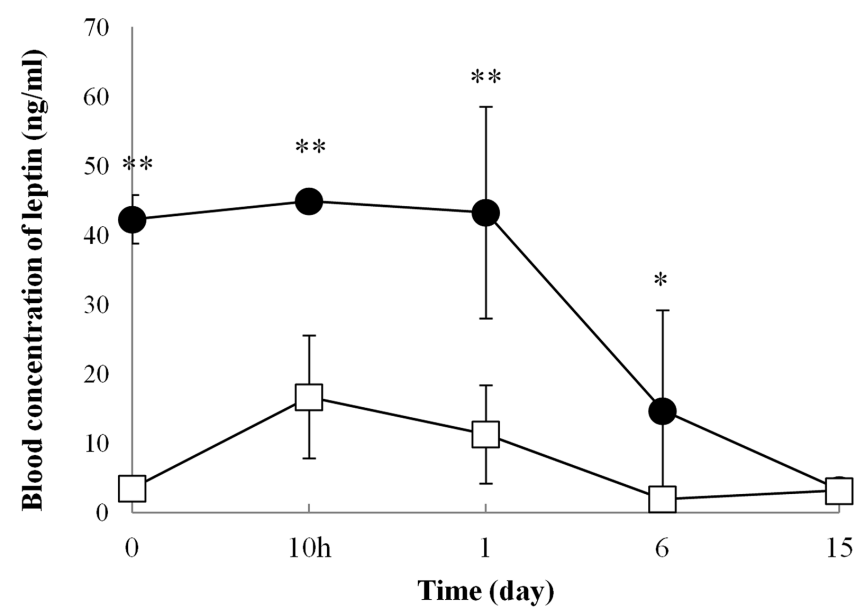

Figure 4. The blood concentration of leptin before and after wounding. Values are means, with their standard deviation represented by vertical bars. Control group $(\square) \mathrm{n}=4,5,6,6$, 5, Diet group $(\bullet) n=5,5,7,8,6$. *, ** Mean value was significantly different from that of the control group (unpaired t-test comparisons: ${ }^{*} \mathrm{p}<0.05,{ }^{* *} \mathrm{p}<0.01$ ).

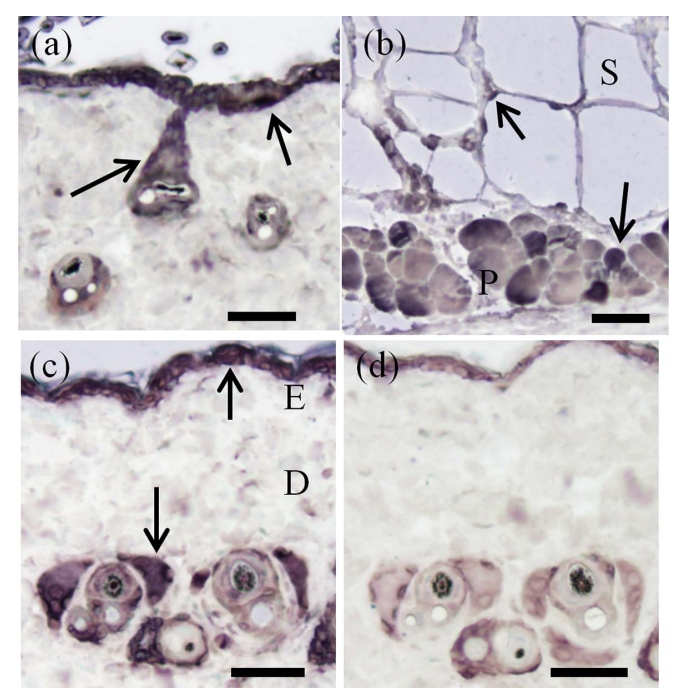

Figure 5. Distribution of leptin at day 0 (non-wounding). (a), (b) were the diet group, and (c), (d) were the control group. (d) was the negative control; it was not incubated with the anti-leptin antibody. Sections were stained with a polyclonal goat anti-leptin antibody. Arrows indicate leptin-positive cells. Magnification: $20 \times$. Scale bar $=50 \mu \mathrm{m}$. E: epidermis; D: dermis; S: subcutaneous adipose tissue; P: panniculus carnosus.

At day 15 after wounding, new epidermis covered almost all of the wound surface. In the diet group, the leptin-positive cells were still present in new epidermis and granulation tissue (Figure 8(a)). At the wound edge, positive cells were present in the epidermal layer, sebaceous gland cells around hair follicles, subcutaneous adipose tissue, and panniculus carnosus (Figure 8(b)). The blood leptin level in the diet group was decreased at day 15 after wounding, however leptin-positive cells were still present in scars, while the leptin-positive cells in the control group were only present in dermis, hair follicles, and subcutaneous adipose tissue (Figure 8(d)). In the epidermis and granulation tissue of the control group, leptin-positive cells were absent (Figure 8(d) and Figure $8(\mathrm{e}))$.

The elevation in leptin was observed to develop progressively, thereby underscoring the continued expression of leptin in the course of the wound-repair process. 


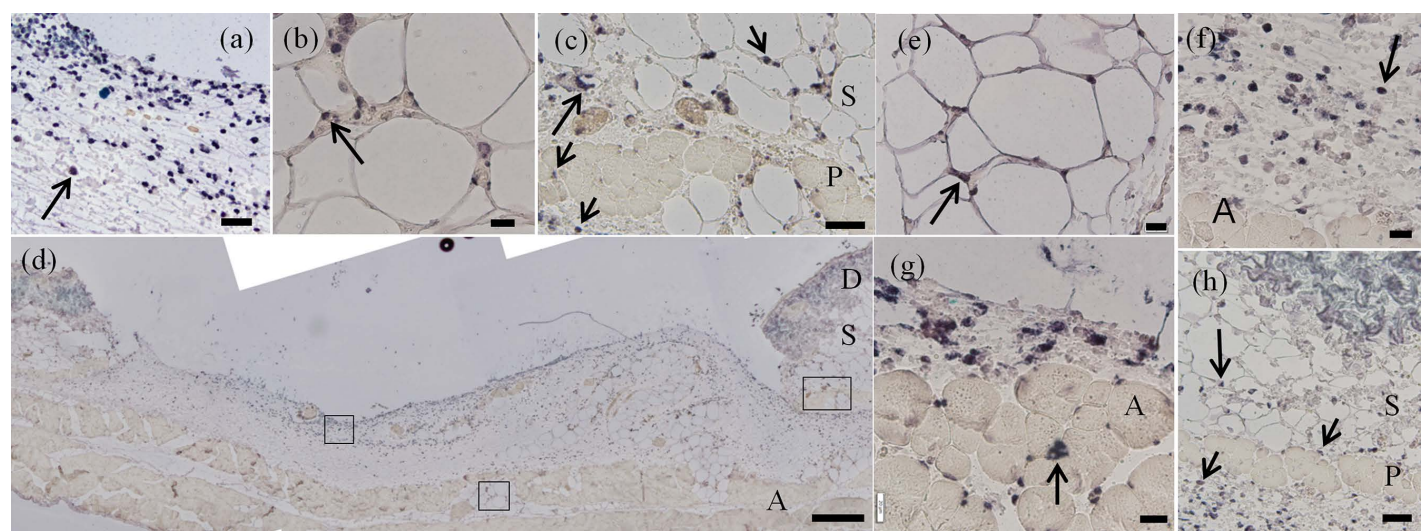

Figure 6. Distribution of leptin $10 \mathrm{~h}$ after wounding. (a)-(d) were the diet group, and (e)-(h) were the control group. (d) was the wound and wound edge in the diet group. Squares show each location of (a), (b), and (c) in the wound. (a), (g) was the center of wound. (b), (e) was near an abdominal muscle in the center of wound. The leptin-positive cells were present in the wound bed, they seemed to be inflammatory cells. (c), (h) was subcutaneous fat in the wound edge. (f) was near an abdominal muscle in the wound edge. The leptin-positive cells were present in subcutaneous adipose tissue, sebaceous gland cells around hair follicles, panniculus carnosus, and inflammatory cells in subcutaneous tissue. Sections were stained with a polyclonal goat anti-leptin antibody. Arrows indicate leptin-positive cells. Magnification: 40× (b), (e), (f), (g), 20× (a), (c), (h), 4× (d). Scale bar = $20 \mu \mathrm{m}$ (b), (e), (f), (g), $50 \mu \mathrm{m}$ (a), (c), (h), $200 \mu \mathrm{m}$ (d). D: dermis; S: subcutaneous adipose tissue; P: panniculus carnosus; A: abdominal muscle.
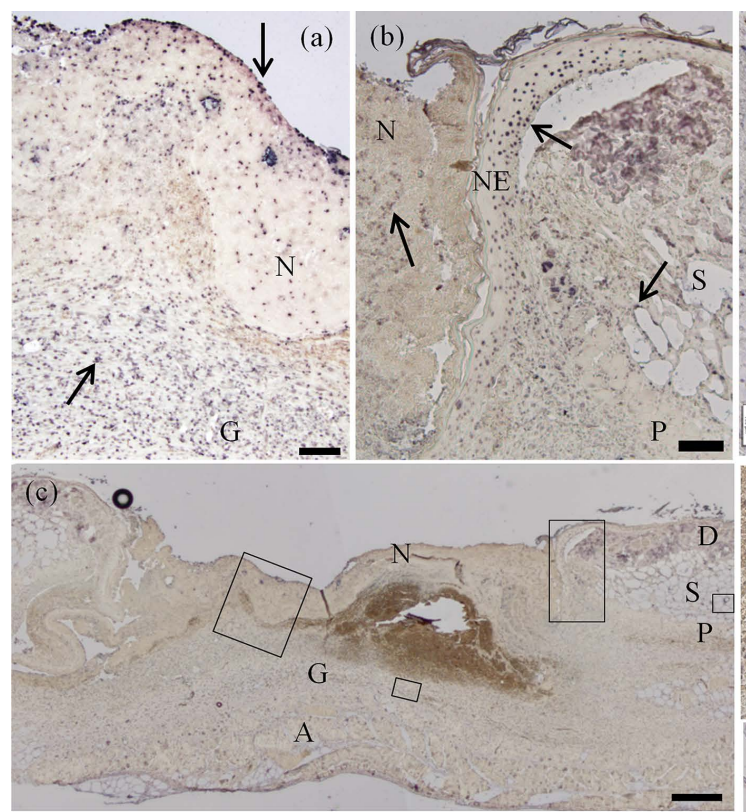

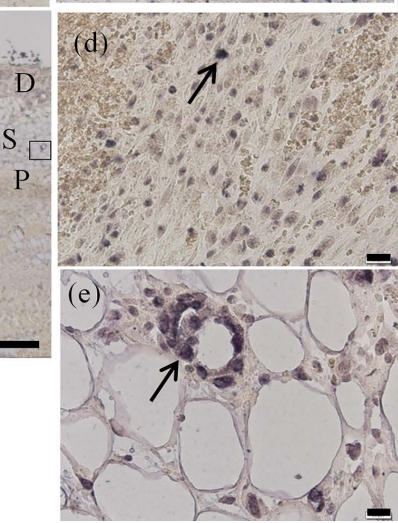

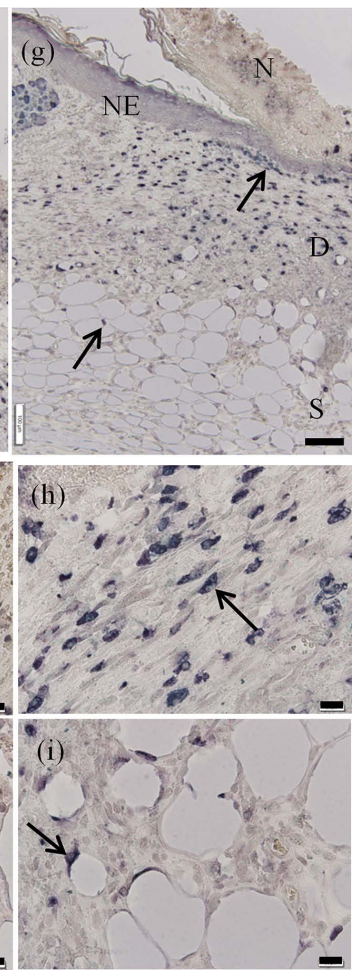

Figure 7. Distribution of leptin at day 6 after wounding. (a)-(e) were the diet group, and (f)-(i) were the control group. (c) was the wound and wound edge in the diet group. Squares show each location of (a), (b), (d) and (e) in the wound. (a), (f) were the center of the wound. (d), (h) were also granulation tissue in the center of the wound. (b), (g) were edges of new epidermis in the wound. (e), (i) were subcutaneous fats in the wound edge. Leptin-positive cells were present around the new epidermis, necrotic tissue, and granulation tissue. At the wound edge, leptin-positive cells were present in subcutaneous adipose tissue. Sections were stained with a polyclonal goat anti-leptin antibody. Arrows indicate leptin-positive cells. Magnification: 40× (d), (e), (h), (i), 20× (a), (b), (f), (g), 4× (c). Scale bar = $20 \mu \mathrm{m}$ (d), (e), (h), (i), $50 \mu \mathrm{m}(\mathrm{a}),(\mathrm{b}),(\mathrm{f}),(\mathrm{g})$, $200 \mu \mathrm{m}$ (c). D: dermis; S: subcutaneous adipose tissue; P: panniculus carnosus; A: abdominal muscle; NE: new epidermis; $\mathrm{N}$ : necrotic tissue; G: granulation tissue. 


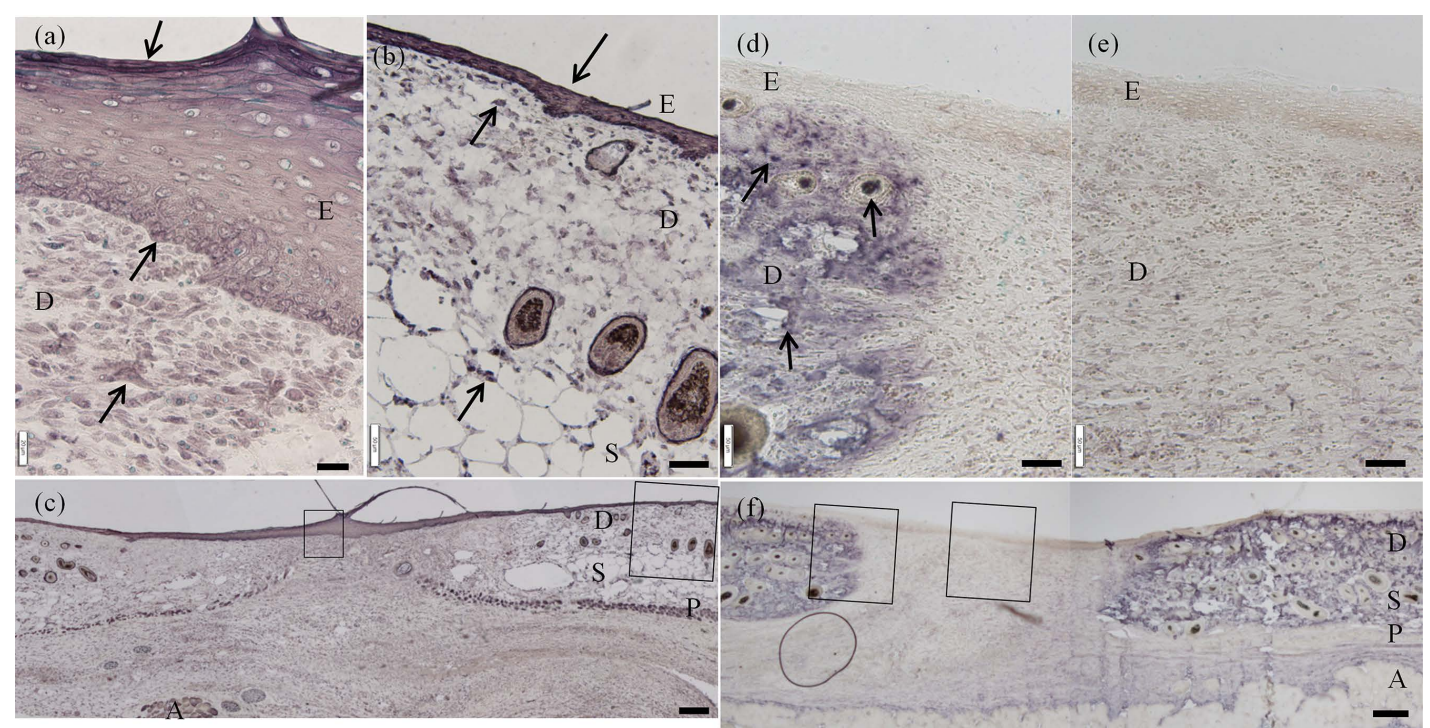

Figure 8. Distribution of leptin at day 15 after wounding. (a)-(c) were the diet group, and (d)-(f) were the control group. (c) was the wound and wound edge in the diet group. Squares show each location of (a) and (b) in the wound. (f) was the wound and wound edge in the control group. Squares show each location of (d) and (e) in the wound. (a), (e) were the center of the wound. (b), (d) were the wound edges. In the diet group, leptin-positive cells were present in scars, while leptinpositive cells were only presented in the dermis, hair follicles, and subcutaneous adipose tissue. Sections were stained with a polyclonal goat anti-leptin antibody. Arrows indicate leptin-positive cells. Magnification: 40× (a), 20× (b), (d), (e), 4× (c), (f). Scale bar $=20 \mu \mathrm{m}$ (a), $50 \mu \mathrm{m}$ (b), (d), (e), $200 \mu \mathrm{m}$ (c), (f). E: epidermis; D: dermis; S: subcutaneous adipose tissue; P: panniculus carnosus; A: abdominal muscle.

\section{Discussion}

Our obese mouse model is suitable for an obese mouse without hyperglycemia. In the diet group, mean body weight was 1.45 times greater than that in the control group, and the mean weight was $45 \%$ higher. The weight of our obese mouse is lower than that of obese rats by Cattaneo: 57\% [15], but heavier than that by Nascimento: 25.7\%, 29\% [12] [13] and Pence: 28\% [14]. In the diet group, the area of body fat using MRI was 2.1 times greater, the thickness of subcutaneous fat was 2.3 times greater, and the epididymal fat mass was 1.5 times higher compared with the control group. These data indicated that the diet group had an excessive accumulation of adipose tissue, that is obesity. To evaluate fat accumulation, body weight [12]-[15], the index of Lee [12] [13] [15], epididymal fat [15], retroperitoneal fat [12] [13] were used in previous studies. There has been no previous study evaluating total body (especially trunk) fat accumulation with MRI. Our evaluation reflected body fat accumulation. Moreover, the fasting BS in the diet group, $152.9 \mathrm{~g} / \mathrm{dl}$, was significantly higher than that in the control group, $119.0 \mathrm{mg} / \mathrm{dl}$. On the other hand, as the fasting BS in ob/ob mice, and GK rats were 295 (SD 66.8) and $229 \mathrm{mg} / \mathrm{dl}$, respectively (industry data, Japan SLC, Inc., Hamamatsu, Japan), the fasting BS of our obese mouse is lower than those of diabetic rodent models like the obese rat [12] [13] [15] and mouse [14] models. Moreover, our diet period of 15 weeks was shorter than that of Cattaneo, 7 months [15], and the same as that as Nascimento [12] [13], and Pence [14]. Therefore, the mice in the diet group would be suitable for an obese model without hyperglycemia.

The ratio of wound area in the diet group did not differ from that in the control group. On day 15, wounds of each group formed scars. This result indicates that wounds healed at the same speed in the two groups. The degree of re-epithelialization and the density of collagen fiber were also not different between the two groups throughout the experiment. The present data did not agree with a previous study [12] [13]. To discuss the reason, weight and feed intake for 15 days after wounding were paid attention to. Our obese mouse lost weight remarkably after wounding. Consequently, mean body weight from day 10 to 15 did not differ significantly between the obese and non-obese mice. After wounding, the degree of diet intake also decreased remarkably in both groups. In the control group, the degree of diet intake returned to the mean level of intake before wounding from day 5. However, in the diet group, the degree of diet intake did not return to the mean level of intake until day 14 . The reason why the obese mouse did not take the high-fat diet is unclear, as the stress by wounding influences both 
the obese and non-obese mouse. In a previous study [12], obesity models also decreased in weight. However, the weight difference was kept for 21 days after wounding. No mention was made of a decrease in feed intake. There have been no reports that an obese animal lost weight without taking in feed after wounding. So we focused on leptin to search for the reason. Leptin, a $16 \mathrm{kDa}$ protein [17], is synthesized by fat cells (adipocytes) and can be shown to circulate in plasma [18]. The appetite-regulating effect of leptin has been reported [17] [19]. After incisional wounds were created in mice, circulating leptin levels increased rapidly, reaching a peak at $12 \mathrm{~h}$ and returning to baseline after $24 \mathrm{~h}$ [16]. We considered whether an increased concentration of leptin acts as an appetite suppressor. Therefore, we measured the blood concentrations of leptin before and after wounding. At day 0 before wounding, $10 \mathrm{~h}$ and day 1 after wounding, the blood concentration of leptin in the obese mouse was significantly higher than in the non-obese mouse. Interestingly, this level in the obese mouse was almost stable before and immediately after wounding. Therefore, this result may indicate that the blood concentration of leptin in obese subjects is not increased by wounding, although leptin synthesis and secretion are primarily dependent on total body fat content [20] and plasma leptin levels are increased in obese persons [21]-[23] and rodents [22]. At day 6 after wounding, this concentration decreased remarkably, but was higher than that of non-obese mice. Finally, there was no difference between the two groups on day 15. On the other hand, leptin levels in non-obese mouse increased after wounding and decreased between 1 and 6 days after wounding with restoring of diet intake. Therefore, the relationship between the leptin levels in obesity and wounding must be further researched.

Topical administration of leptin may be useful as a treatment to promote wound healing in the skin [24]. In addition, leptin is a potent angiogenic factor [16] [24], a mediator of keratinocyte proliferation during wound healing [24] [25], and up-regulator of collagen production by dermal fibroblasts [26]. In this study, during the inflammatory and granulation phase, the blood concentration of leptin in the diet group was significantly higher than that in the control group, and a lot of leptin positive cells were present in the wound area in both the obese and non-obese mice. During these phases, a high concentration of leptin in the diet group might promote wound healing. On the other hand, obesity is associated with a state of chronic, low grade inflammation [27]. The obese body might be in antagonism between the leptin effect and obesity-induced inflammation. However, as body weight in the diet group decreased remarkably in this study, it is possible that obesity-induced inflammation decreases also with leptin effect's increasing relatively. This issue should be resolved in future studies.

In surgical wounds, the increased tension on the wound edges that is frequently seen in obese patients also contributes to wound dehiscence [9] [28] [29]. A continuous facial closure potentially allows even distribution of abdominal-wall tension throughout the wound. The shorter suture length-wound length ratios may be associated with increased wound tension, which may increase tissue pressure, reducing musculofascial microperfusion and perhaps oxygen availability [30]. We measured the value of the differences between the major axis and minor axis of the wound everyday to analyze wound tension. From day 2 to day 8, the difference between the major axis and the minor axis of the wound in the diet group was significantly greater than that in the control group. This result indicates that tension is acting for a longer time than in wounds of the control group, and so this also agrees with literature in which there is tension increase on the wound edges [9]. In the diet group, the shape of the wound was oval in the dorsal and ventral direction, so we think that major tension acts in the dorsal and ventral direction in the body. However, because body weight in the diet group decreased remarkably, mice could not maintain obesity in this study. So we cannot show how tension of an obese body affects wound healing. In this study, we did not measure the value of wound tension. On the other hand, the minor axis of an oval wound is such a short distance that re-epithelialization may occur for a short time. Therefore, we plan to maintain the circle shape of wounds and study the effect of tension on wound healing.

\section{Conclusion}

The mice in the diet group had an excessive accumulation of adipose tissue. However, the body weight in the diet group decreased remarkably after wounding. The blood concentration of leptin in the diet group was almost stable before and immediately after wounding, and this level might not be increased by wounding. The ratio of wound area, re-epithelialization, and collagen fiber did not differ between the diet and control groups. This result would relate that mice could not maintain obesity from day 10 to day 15 after wounding, and it was also unclear of the effect of leptin on the wound. These findings may indicate that the maintenance of a normal weight 
is important for wound healing.

\section{Acknowledgements}

This work was supported by JSPS Grant-in-Aid for Scientific Research(B) Grant Number JP25293430. The authors thank Prof. Tosiaki Miyati for his help in setting for measurement with MRI.

\section{Conflict of Interest}

None of the authors has any conflicts of interest to declare.

\section{References}

[1] Kanazawa, M., Yoshiike, N., Osaka, T., Numba, Y., Zimmet, P. and Inoue, S. (2002) Criteria and Classification of Obesity in Japan and Asia-Oceania. Asia Pacific Journal of Clinical Nutrition, 11, S732-S737. http://dx.doi.org/10.1046/j.1440-6047.11.s8.19.x

[2] Examination Committee of Criteria for "Obesity Disease” in Japan; Japan Society for the Study of Obesity (2002) New Criteria for “Obesity Disease” in Japan. Circulation Journal, 66, 987-992.

[3] Organization, W.H. (2000) Obesity: Preventing and Managing the Global Epidemic. Report of a WHO Consultation. World Health Organization Technical Report Series, 894, 1-253.

[4] Martyn, J.A.J., Kaneki, M. and Yasuhara, S. (2008) Obesity-Induced Insulin Resistance and Hyperglycemia: Etiologic Factors and Molecular Mechanisms. Anesthesiology, 109, 137-148. http://dx.doi.org/10.1097/ALN.0b013e3181799d45

[5] Chan, J.M., Rimm, E.B., Colditz, G.A., Stampfer, M.J. and Willett, W.C. (1994) Obesity, Fat Distributin and Weight Gain as Risk Factors for Clinical Diabetes in Men. Diabetes Care, 17, 961-969. http://dx.doi.org/10.2337/diacare.17.9.961

[6] Colditz, G.A., Willett, W.C., Rotnitzky, A. and Manson, J.E. (1995) Weight Gain as a Risk Factor for Clinical Diabetes Mellitus in Women. Annals of Internal Medicine, 122, 481-486. http://dx.doi.org/10.7326/0003-4819-122-7-199504010-00001

[7] Yoshiike, N., Nishi, N., Matsushima, S., Itou, C., Ikeda, Y., Kashihara, H., Yoshinaga, H., Ogura, H., Komine, S., Sato, Y., Sato, N., Sasaki, A., Fujioka, S., Oku, J., Amemiya, T., Sakata, T. and Inoue, S. (2000) Relation between Body Mass Index and Risk for Diabetes, Hypertension, Hyperlipidemia-An Epidemiological Study by Multicenter Cooperative Study. Himan Kenkyu, 6, 4-17.

[8] Jerant, A., Bertakis, K.D. and Franks, P. (2015) Body Mass Index and Health Care Utilization in Diabetic and Nondiabetic Individuals. Medical Care, 53, 409-416. http://dx.doi.org/10.1097/MLR.0000000000000343

[9] Guo, S. and Dipietro, L.A. (2010) Factors Affecting Wound Healing. Journal of Dental Research, 89, 219-229. http://dx.doi.org/10.1177/0022034509359125

[10] Goodson, W.H. and Hunt, T.K. (1986) Wound Collagen Accumulation in Obese Hyperglycemic Mice. Diabetes, 35, 491-495. http://dx.doi.org/10.2337/diab.35.4.491

[11] Huang, L., Nakagami, G., Minematsu, T., Kinoshita, A., Sugama, J., Nakatani, T., Sagara, H. and Sanada, H. (2010) Ulceration and Delayed Healing Following Pressure Loading in Hyperglycemic Rats with an Immature Dermal Collagen Fiber Network. Wounds, 22, 237-244.

[12] Nascimento, A.P. and Costa, A.M. (2006) Overweight Induced by High-Fat Diet Delays Rat Cutaneous Wound Healing. British Journal of Nutrition, 96, 1069-1077. http://dx.doi.org/10.1017/BJN20061955

[13] Nascimento, A.P. and Costa, A.M. (2011) Both Obesity-Prone and Obesity-Resistant Rats Present Delayed Cutaneous Wound Healing. British Journal of Nutrition, 106, 603-611. http://dx.doi.org/10.1017/S0007114511000468

[14] Pence, B.D., Dipietro, L.A. and Woods, J.A. (2012) Exercise Speeds Cutaneous Wound Healing in High-Fat Diet-Induced Obese Mice. Medicine \& Science in Sports \& Exercise, 44, 1846-1854. http://dx.doi.org/10.1249/MSS.0b013e31825a5971

[15] Cattaneo, L., Gennaro Colonna, V.D., Zoli, M., Müller, E. and Cocchi, D. (1996) Characterization of the Hypothalamo-Pituitary-IGF-I Axis in Rats Made Obese by Overfeeding. Journal of Endocrinology, 148, 347-353. http://dx.doi.org/10.1677/joe.0.1480347

[16] Murad, A., Nath, A.K., Cha, S.T., Demir, E., Flores-Riveros, J. and Sierra-Honigmann, M.R. (2003) Leptin Is an Autocrine/Paracrine Regulator of Wound Healing. The FASEB Journal, 17, 1895-1897.

[17] Halaas, J.L., Gajiwala, K.S., Maffei, M., Cohen, S.L., Chait, B.T., Rabinowitz, D., Lallone, R.L., Burley, S.K. and Friedman, J.M. (1995) Weight-Reducing Effects of the Plasma Protein Encoded by the Obese Gene. Science, 269, 543- 
546. http://dx.doi.org/10.1126/science.7624777

[18] Zhang, Y., Proenca, R., Maffei, M., Barone, M., Leopold, L. and Friedman, J.M. (1994) Positional Cloning of the Mouse Obese Gene and Its Human Homologue. Nature, 372, 425-432. http://dx.doi.org/10.1038/372425a0

[19] Farooqi, I.S. (2014) Defining the Neural Basis of Appetite and Obesity: From Genes to Behaviour. Clinical Medicine (London), 14, 286-289. http://dx.doi.org/10.7861/clinmedicine.14-3-286

[20] Fine, J.B. and Fine, R.M. (1997) Leptin Levels in Obesity. International Journal of Dermatology, 36, 727-728. http://dx.doi.org/10.1046/j.1365-4362.1997.00335.x

[21] Ronnemaa, T., Karonen, S.L., Rissanen, A., Koskenvuo, M. and Koivisto, V.A. (1997) Relation between Plasma Leptin Levels and Measures of Body Fat in Identical Twins Discordant for Obesity. Annals of Internal Medicine, 126, $26-$ 31. http://dx.doi.org/10.7326/0003-4819-126-1-199701010-00004

[22] Maffei, M., Halaas, J., Ravussin, E., Pratley, R.E., Lee, G.H., Zhang, Y., Fei, H., Kim, S., Lallone, R., Ranganathan, S., Kern, P.A. and Friedman, J.M. (1995) Leptin Levels in Human and Rodent: Measurement of Plasma Leptin and $o b$ RNA in Obese and Weight-Reduced Subjects. Nature Medicine, 1, 1155-1161. http://dx.doi.org/10.1038/nm1195-1155

[23] Mendoza-Azpur, G., Castro, C., Peña, L., Guerrero, M.E., De La Rosa, M., Mendes, C. and Chambrone, L. (2015) Adiponectin, Leptin and TNF- $\alpha$ Serum Levels in Obese and Normal Weight Peruvian Adults with and without Chronic Periodontitis. Journal of Clinical and Experimental Dentistry, 7, e380-e386. http://dx.doi.org/10.4317/jced.52350

[24] Tadokoro, S., Ide, S., Tokuyama, R., Umeki, H., Tatehara, S., Kataoka, S. and Satomura, K. (2015) Leptin Promotes Wound Healing in the Skin. PLoS ONE, 10, e0121242. http://dx.doi.org/10.1371/journal.pone.0121242

[25] Frank, S., Stallmeyer, B., Kämpfer, H., Kolb, N. and Pfeilschifter, J. (2000) Leptin Enhances Wound Re-Epithelialization and Constitutes a Direct Function of Leptin in Skin Repair. The Journal of Clinical Investigation, 106, 501-509. http://dx.doi.org/10.1172/JCI9148

[26] Ezure, T. and Amano, S. (2007) Adiponectin and Leptin Up-Regulate Extracellular Matrix Production by Dermal Fibroblasts. BioFactors, 31, 229-236. http://dx.doi.org/10.1002/biof.5520310310

[27] Suganami, T. and Ogawa, Y. (2010) Adipose Tissue Macrophages: Their Role in Adipose Tissue Remodeling. Journal of Leukocyte Biology, 88, 33-39. http://dx.doi.org/10.1189/jlb.0210072

[28] Armstrong, M. (1998) Obesity as an Intrinsic Factor Affecting Wound Healing. Journal of Wound Care, 7, $220-221$.

[29] Wilson, J.A. and Clark, J.J. (2004) Obesity: Impediment to Postsurgical Wound Healing. Advances in Skin \& Wound Care, 17, 426-435. http://dx.doi.org/10.1097/00129334-200410000-00013

[30] Derzie, A.J., Silvestri, F., Liriano, E. and Benotti, P. (2000) Wound Closure Technique and Acute Wound Complications in Gastric Surgery for Morbid Obesity: A Prospective Randomized Trial. Journal of the American College of Surgeons, 191, 238-243. http://dx.doi.org/10.1016/S1072-7515(00)00353-7

\section{Submit or recommend next manuscript to SCIRP and we will provide best service for you:}

Accepting pre-submission inquiries through Email, Facebook, Linkedin, Twitter, etc

A wide selection of journals (inclusive of 9 subjects, more than 200 journals)

Providing a 24-hour high-quality service

User-friendly online submission system

Fair and swift peer-review system

Efficient typesetting and proofreading procedure

Display of the result of downloads and visits, as well as the number of cited articles

Maximum dissemination of your research work

Submit your manuscript at: http://papersubmission.scirp.org/ 